\title{
The Frankenstein's Legacy: Transcranial Direct Current Stimulation in Promoting Speech and Language Recovery in Post- Stroke Dysphasia: Malaysian's Experience
}

\author{
Mohamad Hashim $N^{a}$, Jamil NFF ${ }^{a}$, Ahmad Roslan NF ${ }^{a}$, Mohd Zohdi WN ${ }^{a}$, SF Salim $M^{b}$, Kamarudin SN ${ }^{c}$ \\ a Department of Rehabilitation Medicine, Faculty of Medicine, Universiti Teknologi MARA Malaysia \\ bepartment of Medicine, Faculty of Medicine and Health Sciences, Universiti Putra Malaysia \\ 'Department of Pharmacology, Faculty of Medicine, Universiti Teknologi MARA Malaysia
}

\section{ABSTRACT}

Transcranial Direct Current Stimulation (tDCS) is an adjunct to behavioral speech therapy to enhance the recovery of post-stroke dysphasia. Administration of tDCS involves the application of low- amplitude electrical currents through surface electrodes, which are placed onto the scalp to influence the neuronal activity.TDCS montage and patients' clinical characteristics are the important factors in determining the outcome of the intervention. We aim to describe the clinical characteristics, outcomes and local limitation factors of five post-stroke patients who received TDCS combined with behavioural therapy for dysphasia. All patients, except for Case \#5 showed improvement at day 10 post-intervention in several speech and language domains. TDCS is a promising adjunctive intervention in enhancing neuroplasticity activity in a post-stroke brain. A further well design case-controlled study is warranted to prove its efficacy in our local population. Local factors and limitations that may influence the outcome should be considered.

KEYWORDS: Transcranial direct current stimulation, stroke, dysphasia, factors, limitation

\section{INTRODUCTION}

Stroke is among the top leading causes of mortality in Malaysia and around the world. ${ }^{1}$ Statistics showed an increasing trend of incidence and prevalence in a prospective study from 2010- 2014 on Malaysia's population. ${ }^{1}$ This study revealed growth of nearly triple of incidence and prevalence of ischemic stroke in the 5-year period (34.2-96.2 per 100,000), while those of hemorrhagic stroke increased at a lower rate (10.6-21.1 per 100,000). ${ }^{1}$ According to the Third Malaysian Burden of Disease and Injury (MBOD) study undertaken in 2014, stroke is at the 3rd place among the leading causes of total burden in Malaysia for 2014, contributing $7.9 \%$ of total disability-adjusted life year (DALYs). ${ }^{2}$

Upon being discharged from the hospital, about onethird of adult stroke patients suffer from aphasia and

Corresponding Author:

Dr. Natiara binti Mohamad Hashim Department of Rehabilitation Medicine, Faculty of Medicine, Universiti Teknologi Mara, Sg. Buloh Campus, Jalan Hospital, $47000 \mathrm{Sg}$. Buloh, Selangor, Malaysia.

Tel No : +6019-3803105

Email : natiara@uitm.edu.my almost $20 \%$ of all stroke survivors have chronic aphasic symptoms. ${ }^{3}$ Speech and language disorder has shown to impact the quality of life, associated with a high incidence of depression and reduces community participation. ${ }^{4}$

Various restorative interventions have been described in the rehabilitation of speech and language disorder which includes behavioural therapy and pharmacological treatment. ${ }^{5}$ Transcranial Direct Current Stimulation (tDCS) is an adjunct to conventional behavioral speech therapy to enhance the recovery of post-stroke dysphasia. ${ }^{6}$ Administration of tDCS involves the application of low-amplitude electrical currents through surface electrodes which are placed onto the scalp to influence the neuronal activity by modulating cortical excitability. ${ }^{6}$

TDCS already garnered popularity amongst developed countries in integrating this intervention with conventional therapies in achieving a maximal outcome in speech and language disorder. 6,7 TDCS is still new in Malaysia and limited literature has described its effectiveness among our local 


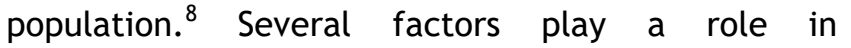
determining of its effectiveness and rehabilitation outcome: montage of stimulation (anodal or cathodal stimulation), duration and location of stimulation, voltage, method of other combined therapy and patients' clinical characteristics ${ }^{6}$ (reference). The objective of this case series is to describe the clinical characteristics of our five poststroke patients who received TDCS combined with behavioural therapy for dysphasia and their outcomes post-intervention. We also will be discussing the local factors and limitations illustrated from these five cases that may influence the outcome of this adjunctive intervention.

\section{CASE SERIES}

Objective: We described the clinical characteristics of our five post-stroke patients who received TDCS combined with behavioural speech therapy, the difference in their outcomes, identifying factors and limitations we encountered during this multimodal intervention.

Recruitment: We have recruited five patients who fulfilled the inclusion and exclusion criteria to attend conventional intensive speech and language therapies combined with TDCS. The inclusion criteria were as follows; 1) Post hemorrhagic or ischemic stroke 2) Receptive or Expressive 3) Able to obey at least one- step simple command. The exclusion criteria were as followed; 1) Global Aphasia 2) Seizure 3) Acute stroke less than 6 months. 4) Patients who underwent de-compressive craniectomy. We summarized the characteristics of our patients in Table 1.

Intervention: All five patients underwent baseline assessment to classify their speech and language impairment according to Boston Speech and Language Classification. All patients received 10 sessions of TDCS stimulation for 20 minutes duration combined with simultaneous behavioral speech therapies for 1 hour.The TDCS montage for each patient is summarized in Table 2 . The location of electrode placement was determined using 10- 20 electroencephalography (EEG) electrode positioning system. Post-intervention assessment on speech and language domains which was applicable to each patient was measured upon completion of 10 sessions. The outcomes of these patients are summarized in Table 3.

\section{DISCUSSION}

Case 1 has shown remarkable improvement compared to other patients in all domains of speech tested in speed, spontaneity, speech intelligibility, and fluency. This may also be due to minimal impairment at the baseline compared to other patients across the speech and language domains. Nevertheless, all patients have shown vast improvement in speed and naming spontaneity in the domain of naming common objects. These findings were consistent with a systematic review and metanalyses, in which many evidence has shown the most improvement seen in the domain of naming objects. ${ }^{6,7}$ However, the lack of evidence to show the improvement in this domain does not really reflect the functional improvement, which requires

Table 1: Clinical characteristics of recruited post stroke patients with speech and language disorder

\begin{tabular}{|c|c|c|c|c|c|c|c|}
\hline Patient & Age & Ethnicity & $\begin{array}{l}\text { Type of } \\
\text { Stroke }\end{array}$ & $\begin{array}{l}\text { Duration } \\
\text { Post - } \\
\text { stroke }\end{array}$ & Onset & $\begin{array}{l}\text { Type of Speech } \\
\text { and Language } \\
\text { Disorder }\end{array}$ & Radiological Findings \\
\hline Case 1 & 78 & Malay & $\begin{array}{l}\text { Left } \\
\text { Ischemic } \\
\text { Stroke }\end{array}$ & 5 years & First & $\begin{array}{l}\text { Expressive } \\
\text { Dysphasia and } \\
\text { Speech Apraxia }\end{array}$ & $\begin{array}{l}\text { Infarction of left corona } \\
\text { radiata, left insula and } \\
\text { left anterior temporal } \\
\text { lobe }\end{array}$ \\
\hline Case 2 & 71 & Malay & $\begin{array}{l}\text { Left } \\
\text { Ischemic } \\
\text { Stroke }\end{array}$ & 3 years & First & $\begin{array}{l}\text { Expressive } \\
\text { Dysphasia and } \\
\text { Speech Apraxia }\end{array}$ & $\begin{array}{l}\text { Infraction of left } \\
\text { temporal lobe }\end{array}$ \\
\hline Case 3 & 55 & Malay & $\begin{array}{l}\text { Left } \\
\text { Hemorrhagic } \\
\text { Stroke }\end{array}$ & 4 years & Recurrent & $\begin{array}{l}\text { Expressive } \\
\text { Dysphasia }\end{array}$ & $\begin{array}{l}\text { Haemorrhage involving } \\
\text { left basal ganglia and } \\
\text { thalamus with } \\
\text { intraventicular } \\
\text { extension }\end{array}$ \\
\hline Case 4 & 54 & Malay & $\begin{array}{l}\text { Left } \\
\text { Ischemic } \\
\text { stroke }\end{array}$ & 4 years & First & $\begin{array}{l}\text { Expressive } \\
\text { Dysphasia }\end{array}$ & $\begin{array}{l}\text { Multifocal infarction } \\
\text { with generalized } \\
\text { cerebral atrophy }\end{array}$ \\
\hline Case 5 & 65 & Indian & $\begin{array}{l}\text { Left } \\
\text { Ischemic } \\
\text { Stroke }\end{array}$ & 8 months & First & $\begin{array}{l}\text { Mixed } \\
\text { Transcortical } \\
\text { Dysphasia }\end{array}$ & $\begin{array}{l}\text { Infarction of left } \\
\text { temporal and } \\
\text { frontoparietal lobes }\end{array}$ \\
\hline
\end{tabular}


further investigations. ${ }^{7}$ Across all these patients, Case $\mathbf{5}$ has demonstrated the least improvement and also regression in the domain of describing verb objects. Factors that may influence these findings were; 1 . Patient has impairment in the receptive domain in speech even though in a limited extend, hence, hindering the understanding during behavioral therapy delivery; 2 . The patient was an Indian ethnicity, of which his first spoken and mother tongue language was Tamil language. However, he was able to understand and speak in Malay Language before the stroke onset. This may become a confounding factor to the effectiveness of the therapy as the delivery of conventional therapy was mainly in Malay Language. 3. The area of infarction involved both the temporal (Wernicke's) and frontoparietal (Broca's) area compared to other cases. 4. The patient had a 4 days gap in between therapies despite completing 10 sessions, which may have disturbed the continuity of the intervention. post-stroke have demonstrated that there was a reduction of transcollosal inhibition from the left hemisphere towards the right contralateral homologs speech area. This change leads to a greater excitation of the right homologous area, which imposes further inhibition towards the activity of the left hemisphere. ${ }^{6}$ TDCS anodal stimulation towards the left peri-lesional area may increase the transcallosal inhibition to the right contralateral hemisphere, hence increase the neuro-recovery of the left speech center.

Other factors such as type of behavioral therapies may also play a significant role. The mode of delivery, whether it was given online (simultaneous delivery of behavioral therapy during stimulation) or offline (behavioral therapy given before or after TDCS stimulation), frequency and intensity. ${ }^{6}$ Many studies have shown that offline TDCS did not confer good results. ${ }^{6}$

Table 2: Montage of Transcranial Direct Stimulation

\begin{tabular}{|c|c|c|c|c|c|}
\hline TDCS Montage & Case 1 & Case 2 & Case 3 & Case 4 & Case 5 \\
\hline Amplitude & $1 \mathrm{~mA}$ & $1 \mathrm{~mA}$ & $1.5 \mathrm{~mA}$ & $1.5 \mathrm{~mA}$ & $2 \mathrm{~mA}$ \\
\hline Cycle & 10 sessions & 10 sessions & 10 sessions & 10 sessions & 10 sessions \\
\hline Duration per session & 20 mins & 20 mins & 20 mins & 20 mins & 20 mins \\
\hline Location of Stimulation & F3 ( Anodal ) & F3 ( Anodal) & F3 ( Anodal ) & F3 ( Anodal ) & F3 ( Anodal ) \\
\hline Adverse Event & Nil & Nil & Nil & Nil & Nil \\
\hline Combine Therapy & Online & Online & Online & Online & Online \\
\hline
\end{tabular}

${ }^{*} \mathrm{~F} 3$ corresponds to left dorsalateral prefrontal cortex

There are several factors besides patient clinical characteristics that may have influenced the outcomes, which include technical aspects of TDCS delivery. In all our cases, all five patients have received a standardized TDCS montage of $1 \mathrm{~mA}$ to $1.5 \mathrm{~mA}$, except for Case 5 who received a slightly higher amplitude of $2 \mathrm{~mA}$. We excited the $\mathrm{F} 3$ area, which corresponds to the left dorsolateral prefrontal cortex (DLPFC). Several studies have shown anodal stimulation to this area improved object naming, repetition, fluency and verb naming. ${ }^{9}$ The left DLPFC has been associated with many language-related processes, including verbal production, sentence processing. ${ }^{9}$ Numbers of TDCS sessions, amplitude and stimulation duration administers were consistent with many literatures which vary from 1 session up to 18 sessions and 10 mins to 20 mins duration of stimulation duration. ${ }^{6,7}$ The significant improvement of the TDCS has been shown to be dosedependent. ${ }^{10}$ Neurophysiological changes that occur

\section{Limitation of Case Studies in a Local Context}

To the best of the researcher's knowledge, there is a lack of studies reporting on Malaysia's experience in utilizing TDCS as an adjunct intervention in speech and language disorder. Identifying limitations in our local context is crucial to ensure a good outcome if TDCS is to be utilized in upgrading the current state of rehabilitation intervention. These case series illustrate some of the following limitations; 1. Lacking of validated standardized outcome measures in the Malay language. Many high qualities study has utilized Western Aphasia Battery or Boston Diagnostic Aphasia Examination to measure their outcome. ${ }^{6,7}$ Only Boston Naming Test that has been validated in a Malay Language Version, however, its usage only limited to naming activities. ${ }^{11}$ 2. Malaysia consists of multi-linguistic populations' background, hence, the spoken primary language might be different individually. This particular factor also plays a role in the delivery of 
Table 3: Baseline and Outcome in Speech and Language Domains

\begin{tabular}{|c|c|c|c|c|c|}
\hline \multirow[t]{2}{*}{$\begin{array}{l}\text { Speech } \\
\text { Domain }\end{array}$} & \multicolumn{5}{|c|}{ Naming Common Object } \\
\hline & Case 1 & Case 2 & Case 3 & Case 4 & Case 5 \\
\hline Baseline & $\begin{array}{l}\text { Time: } 2 \text { mins } \\
\text { Score: } \\
\text { 100\% sp }\end{array}$ & $\begin{array}{l}\text { Time : } 6 \text { mins } \\
\text { Score : } \\
60 \% \text { sp } \\
10 \% \text { ic } \\
30 \% \text { i }\end{array}$ & $\begin{array}{l}\text { Time : } 4 \text { mins } \\
\text { Score : } \\
100 \% \text { sp } \\
100 \% g\end{array}$ & $\begin{array}{l}\text { Time }:>10 \text { min } \\
\text { Score : } \\
10 \% \text { sp, } 90 \text { I with } \\
0 / 9 \text { accuracy }\end{array}$ & $\begin{array}{l}\text { Time : }>10 \text { mins } \\
\text { Score : } \\
20 \% \text { ic } \\
80 \% \text { i }\end{array}$ \\
\hline \multirow[t]{2}{*}{$\begin{array}{l}\text { Post- } \\
\text { Intervention }\end{array}$} & $\begin{array}{l}\text { Time : } 1 \text { min } \\
\text { Score : } \\
100 \% \text { sp }\end{array}$ & $\begin{array}{l}\text { Time : } 3 \mathrm{~min} \\
\text { Score : } \\
90 \% \text { sp } \\
10 \% \text { ic }\end{array}$ & $\begin{array}{l}\text { Time : } 2 \text { min } \\
\text { Score : } \\
100 \% \mathrm{sp} \\
100 \% \mathrm{~g}\end{array}$ & $\begin{array}{l}\text { Time : } 8 \text { mins } \\
\text { Score : } \\
20 \% \text { sp } \\
60 \% \text { ic } \\
20 \% \text { i }\end{array}$ & $\begin{array}{l}\text { Time : } 5 \text { mins } \\
\text { Score : } \\
10 \% \text { sp } \\
70 \% \text { ic } \\
20 \% \text { i }\end{array}$ \\
\hline & \multicolumn{5}{|c|}{ Describing Verb Objects } \\
\hline Base- line & $\begin{array}{l}\text { Time : } 5 \text { mins } \\
\text { Score : } \\
100 \% \mathrm{sp} \\
90 \% \mathrm{~g} \\
10 \mathrm{nf}\end{array}$ & $\begin{array}{l}\text { Time : } 4 \text { mins } \\
\text { Score : } 50 \% \text { sp } \\
40 \% \text { i } \\
10 \% \text { ic }\end{array}$ & $\begin{array}{l}\text { Time : } 3 \text { mins } \\
\text { Score : } \\
93 \% \text { sp } \\
7 \% \text { ic }\end{array}$ & NA & $\begin{array}{l}\text { Time : } 5 \text { mins } \\
80 \% \text { sp } \\
10 \% \text { ic }\end{array}$ \\
\hline $\begin{array}{l}\text { Post } \\
\text { Intervention }\end{array}$ & $\begin{array}{l}\text { Time : } 3 \text { mins } \\
\text { Score : } \\
100 \% \text { sp } \\
100 \% \mathrm{f}\end{array}$ & $\begin{array}{l}\text { Time : } 3 \text { mins } \\
\text { Score : } \\
90 \% \text { sp } \\
10 \% \text { ic }\end{array}$ & $\begin{array}{l}\text { Time : } 1 \mathrm{~min} \\
\text { Score : } \\
100 \% \mathrm{sp} \\
100 \% \mathrm{~g}\end{array}$ & NA & $\begin{array}{l}\text { Time : } 5 \text { mins } \\
100 \% \text { ic }\end{array}$ \\
\hline & \multicolumn{5}{|c|}{ Answering Self Related Questions } \\
\hline Baseline & $\begin{array}{l}\text { Time : } 6 \text { mins } \\
100 \% \mathrm{sp} \\
100 \% \mathrm{~g}\end{array}$ & $\begin{array}{l}\text { Time ; } 1 \text { min } \\
100 \% \mathrm{sp} \\
100 \% \mathrm{~g}\end{array}$ & $\begin{array}{l}\text { Time : } 1 \mathrm{~min} \\
100 \% \mathrm{sp} \\
100 \% \mathrm{~g}\end{array}$ & NA & NA \\
\hline \multirow[t]{2}{*}{$\begin{array}{l}\text { Post- } \\
\text { Intervention }\end{array}$} & $\begin{array}{l}\text { Time : } 4 \text { mins } \\
100 \% \mathrm{sp} \\
100 \% \mathrm{~g}\end{array}$ & $\begin{array}{l}\text { Time ; } 1 \text { min } \\
100 \% \mathrm{sp} \\
100 \% \mathrm{~g}\end{array}$ & $\begin{array}{l}\text { Time : } 50 \text { secs } \\
100 \% \mathrm{sp} \\
100 \% \mathrm{~g}\end{array}$ & NA & NA \\
\hline & Reading Aloud & n Words & & & \\
\hline Base - line & $\begin{array}{l}\text { Time : } 4 \text { mins } \\
\text { Score : } \\
70 \% \text { sp } \\
30 \% \text { i }\end{array}$ & NA & NA & $\begin{array}{l}\text { Time : >10 mins } \\
\text { Score : } \\
10 \% \text { sp } \\
90 \% \text { i } \\
0 \text { accuracy }\end{array}$ & NA \\
\hline $\begin{array}{l}\text { Post } \\
\text { Intervention }\end{array}$ & $\begin{array}{l}\text { Time : } 50 \text { secs } \\
\text { Score : } \\
100 \% \text { sp }\end{array}$ & NA & NA & $\begin{array}{l}\text { Time : >10 mins } \\
\text { Score : } \\
20 \% \text { sp } \\
60 \% \mathrm{i} / \mathrm{c} \\
0 \text { accuracy }\end{array}$ & NA \\
\hline
\end{tabular}

\section{*Abbreviations:}

Time: Duration to complete tasks required

sp : spontaneous naming

$\mathrm{g}$ : fluent

nf : not fluent

ic : naming with initial syllable cue

I : imitate

g : good intelligibility

NA: not applicable 
behavioural task during conventional therapy, which most likely limited to what language is spoken by the speech and language therapists that might not match what is primarily spoken by the patients. 3 . Lack of functional MRI that determines the highest $Z$ scores or transcranial magnetic stimulation or TMS that determine the hot spots to accurately locate the peri-lesional region to precisely stimulate this area. ${ }^{6} .4$. These case series did not demonstrate and measure the sustainable improvement achieved at least 1 -month post-intervention. By determining these factors through the case series, limitations can be addressed and overcome if any high-quality studies are intended to be carried out among our populations. In addition, this case series also may assist in the selection of patient that may or may not benefit from this intervention.

\section{CONCLUSION}

TDCS can produce some promising results if combined with conventional therapies. Certain factors have to be taken into account in deciding the mode of therapy in ensuring good outcomes of this combined adjunctive therapy. The case series gave an overview of the possible local factors that may play a role and limitations that have to be considered if any high qualities study to be conducted locally.

\section{REFERENCES}

1. Aziz ZA, Lee YY, Ngah BA, et al. Acute stroke registry Malaysia, 2010-2014: results from the National Neurology Registry. Journal of Stroke and Cerebrovascular Diseases 2015; 24: 2701 2709.

2. Malaysian Burden of Disease and Injury. In: 2017 IfPHI, (ed.). Malaysia2009-2014.

3. Pedersen PM, Stig Jørgensen $\mathrm{H}$, Nakayama $\mathrm{H}$, et al. Aphasia in acute stroke: incidence, determinants, and recovery. Annals of Neurology: Official Journal of the American Neurological Association and the Child Neurology Society 1995; 38: 659-666.

4. Cruice $M$, Worrall L, Hickson L, et al. Finding a focus for quality of life with aphasia: Social and emotional health, and psychological wellbeing. Aphasiology 2003; 17: 333-353.

5. Teasell R, Foley N, Salter K, et al. Evidencebased review of stroke rehabilitation: executive summary. Topics in stroke rehabilitation 2009; 16: 463-488.

6. Biou $\mathrm{E}$, Cassoudesalle $\mathrm{H}$, Cogné $\mathrm{M}$, et al. Transcranial direct current stimulation in post -stroke aphasia rehabilitation: a systematic review. Annals of physical and rehabilitation medicine 2019; 62: 104-121.

7. 7Elsner B, Kugler J, Pohl M, et al. Transcranial direct current stimulation (tDCS) for improving aphasia in adults with aphasia after stroke. Cochrane Database of Systematic Reviews 2019.

8. Section HTA. Transcranial Direct Current Stimulation (tDCS) for Stroke Rehabilitation. 2016. Ministry Of Health Malaysia.

9. Pestalozzi MI, Di Pietro M, Martins Gaytanidis $C$, et al. Effects of prefrontal transcranial direct current stimulation on lexical access in chronic poststroke aphasia.

Neurorehabilitation and neural repair 2018;

32: $913-923$

10. Rosso C, Arbizu C, Dhennain C, et al. Repetitive sessions of tDCS to improve naming in post-stroke aphasia: Insights from an individual patient data (IPD) meta-analysis. Restorative neurology and neuroscience 2018; 36: 107-116.

11. Van Dort S, Vong E, Razak RA, et al. Normative data on a Malay version of the Boston Naming Test. Jurnal Sains Kesihatan Malaysia (Malaysian Journal of Health Sciences) 2007; 5. 